\title{
Technical Brokering of Immigrant Adolescents in Switzerland: A Developmental-Acculturative Perspective
}

\author{
Lara Aumann (i) ${ }^{1} \cdot$ Peter F. Titzmann $\mathbb{B}^{1}$ \\ Accepted: 30 October 2021 / Published online: 11 November 2021 \\ (c) The Author(s) 2021
}

\begin{abstract}
In the present digital age, intrafamilial dynamics and adolescents' support of their parents in media use (technical brokering, Katz, 2010) are increasing in attention. However, the significance of migration-specific processes in adolescents' technical brokering is less understood. In immigrant families, adolescents' technical brokering may help families in adapting to the host culture and in keeping contact with friends and family abroad. This study investigated differences in the level of technical brokering between German immigrant and native Swiss adolescents and tested whether migration-unrelated (family life) or migration-related (i.e., culture brokering, Tse, 1995) factors are better predictors of interindividual differences in technical brokering in high SES immigrant families. The sample comprised 301 adolescents in Switzerland: 136 German immigrant adolescents (average age $=15.3,65 \%$ female) and 165 native Swiss adolescents (average age $=15.9,61 \%$ female). Adolescents stated the frequency of technical brokering tasks as well as culture brokering and migration-related processes. The results revealed that German immigrant adolescents provided technical brokering more frequently than native Swiss adolescents. Hierarchical regressions confirmed that technical brokering in German immigrant families is best explained by adolescents' supporting their family in mastering the transition to a new country, as predictors pertaining to culture brokering, and host culture orientation explained most of the variance. This interpretation received further support by an interaction effect showing that technical brokering is particularly frequent when adolescents act as a culture broker in families with substantial socio-cultural adaptation difficulties. This study complements an often deficit-oriented view on immigrant youth with a view of their active and constructive role in immigrant family processes.
\end{abstract}

Keywords Brokering $\cdot$ Family support $\cdot$ Migrant Adolescents $\cdot$ Comparative $\cdot$ ICT

\section{Highlights}

- This comparative immigrant/nonimmigrant study investigated adolescents' supporting their parents in technical tasks (technical brokering).

- Adolescents in both ethnic groups reported technical brokering showing the normativity of such behavior in the technological age.

- Immigrant adolescents reported a higher frequency than their nonimmigrant peers revealing a migration-specific task load.

- In the immigrant sample, technical brokering seems to be associated with adolescents' supporting their family in mastering the transition to a new country.

- This study views the active and constructive role of (immigrant) adolescents in families and societies.

Lara Aumann

aumann@psychologie.uni-hannover.de

1 Department of Psychology, Leibniz University Hanover, Schloßwender Straße 1, 30159 Hanover, Germany
Understanding family dynamics is increasingly gaining attention in research on the acculturation process of immigrant families. In particular, the phenomenon that immigrant adolescents (have to) support their families in various domains (e.g., translating documents, assisting parents with authorities) is growing in awareness because it 
seems to be associated with immigrant adolescents' psychosocial functioning and families' socio-cultural adaptation (Weisskirch, 2020). In this context, different forms of support have been identified with previous research highlighting culture brokering and technical brokering in particular. Culture brokering is a migration-related adolescent support for parents and comprises adolescents' support for parents in the adaptation process in a new society (Tse, 1995). Technical brokering is a migration-unspecific phenomenon in families and describes adolescents' supporting behavior with regard to new technologies (Katz, 2010). Although technical brokering was not originally developed to study immigrant families' adaptation, it moved into the focus of immigration research because information and communication technologies (ICT) can be assumed to support acculturative processes (Guan, 2017; Katz, 2010). However, a perspective that combines developmentalfamilial and acculturative approaches on ICT-related helping behaviors in immigrant families as well as insights into how different forms of brokering (e.g., cultural brokering and technical brokering) interact with each other are still rather rare (Fawcett, 2018). To shed some light on these questions, this study investigated (a) whether immigrant and native adolescents differ in technical brokering, (b) which migration-related or general, developmental processes reinforce technical brokering in immigrant families, and (c) under which conditions migration-specific helping behavior in form of culture brokering is particularly associated with technical brokering. In this study, we applied these research questions to German immigrant and native Swiss adolescents in Switzerland with a high socio-economic status (SES) to overcome the confounding of migration and low socio-economic standing, which has been criticized in acculturation research (Wang \& Miller, 2020).

\section{Adolescents' Support for Their Parents}

Previous research has shown that immigrant adolescents support their parents and other family members in daily life more than native adolescents (Titzmann, 2012). One often demonstrated domain of support in immigrant families concerns adolescents' support in cultural tasks, i.e., adolescents supporting their parents in host culture communication, behavior, and/or norms (Tse, 1995; Weisskirch, 2020). This phenomenon is described as culture brokering (Tse, 1995) and commonly explained by children and adolescents adjusting at a faster pace to a new society and often outperforming their parents in sociocultural skills related to the new cultural context-socalled acculturation gaps (Cheung et al., 2011; Telzer, 2010). Culture brokering has also been shown to generalize to other (migration-unrelated) forms of support, such as instrumental (family decision-making) and emotional (family well-being) family support (Aumann \& Titzmann, 2020; Jurkovic, 1997; Kam \& Lazarevic, 2014).

Adolescents, however, also support their parents in domains that are independent of migratory processes. In the modern digital area, support for parents in media and ICT use has been growing in attention. Qualitative and mixed-method designs (e.g., Correa, 2014; Correa et al., 2019) as well as quantitative methods (Livingstone \& Haddon, 2009) in this area have confirmed intrafamilial helping processes in ICT use (technical brokering; Katz, 2010) and intergenerational differences in ICT competence. The younger generation has been found to be particularly active ICT users and the quickest to learn ICT skills, in particular compared to their parents (JIM, 2018; Kam \& Lazarevic, 2014; Moser, 2009). Thus, as "digital natives" (Prensky, 2001), adolescents are often an important and efficient family resource when it comes to technical support-independent of immigrant background, ICT skills or parental education (e.g., Correa et al., 2015; Livingstone, 2003; Yip et al., 2016). The literature review on ICT use in families also implies that technical brokering may have (at least) two different functions: First, adolescents support parents in ICT use if parents lack the competences required. Second, adolescents support parents, despite the fact that parents have these competences, because adolescents are more efficient and save their parents' time for other tasks and responsibilities (Kam \& Lazarevic, 2014).

Assuming tasks and responsibilities in adolescence is an important aspect of family involvement and a normative process in development, as it enables the development of competencies and a sense of responsibility (Pedersen \& Revenson, 2005). For this reason, technical brokering is a form of support, which can occur in all families independent of immigrant background or socio-economic standing. Highly educated work migrant parents, for instance, may also rely on such support, because their jobs and responsibilities are time-intense (Aumann \& Titzmann, 2020; Moser, 2009). Research on technical brokering and its impact on adolescent and family dynamics are particularly salient with regard to the technological progress in recent decades (Livingstone \& Haddon, 2009; Van den Bulck et al., 2016). The number of internet users aged 14 years and above in German-speaking areas rose from $37 \%$ to $86 \%$ from 2001 to 2019 and over $90 \%$ of youths in Western Europe reported owning a smartphone in 2018 (Statista, 2020). Not surprisingly, ICT competence is now even regarded as a new developmental task for the adolescent years (Hurrelmann \& Quenzel, 2018).

The specific role of adolescents' technical brokering in immigrant families, however, has received less attention 
although an acculturation-specific perspective can add to our understanding of technical brokering in this population (Fawcett, 2018). Acculturation refers to individual processes of change in customs, activities, identification, and values following intercultural contact (Redfield et al., 1936). This intercultural contact can include more than two groups and cultures (Morris et al., 2015), can take place without direct contact (remote acculturation; Ferguson et al., 2017), and sometimes is a life-long process (Oppedal \& Toppelberg, 2016). Technical brokering may play a prominent role in acculturation processes as ICT can serve different purposes for immigrant families (Guan, 2017; Moser, 2009). ICT is often the primary medium for communication with the extended family and friends abroad; provides access to information about the host society; enables immigrants' connecting to the new environment; and is a useful tool from which to learn and adapt to the language and values of the host society (Elias, 2013; Guan, 2017; Katz, 2011). From this perspective, technical brokering may be particularly salient among immigrant families.

In sum, technical brokering in immigrant families can be viewed from a developmental (intrafamilial adolescent responsibility) perspective or from an acculturation-related (immigrant adolescents' support of family adaptation) perspective. The combination of both these perspectives has been mentioned as urgent need in recent acculturation research (Juang \& Syed, 2019; Schwartz et al., 2020). For explaining interindividual differences in technical brokering in immigrant families this means that predictors pertaining to family dynamics have to be combined with predictors pertaining to acculturation (Fawcett, 2018; Guan, 2017). Some of these associations have been addressed in the past. Katz (2010), for example, examined both adolescents' translation activities (culture brokering) and support in ICT use in immigrant families. The systematic investigation of whether general family-related predictors or acculturationrelated variables explain variance in immigrant adolescents' technical brokering is, however, still pending. This is the first research gap that our study addressed. The second research gap is a focus on high SES immigrant families. Most research on immigrant families targets low-income families in the US, which often results in migration processes and vulnerability due to low socio-economic standing being confounded (Wang \& Miller, 2020). Hence, research on high SES families with access to ICT and on highly educated parents allows new insights into acculturative processes in general and functions and reasons of technical brokering in particular (Favell, 2008; Katz, 2010). To shed some light on this research gap, we investigated migration-specific and migration-unrelated aspects of technical brokering in high SES German immigrant families in Switzerland in comparison to native Swiss families.

\section{German Immigrant Families in Switzerland}

To investigate technical brokering in immigrant families without the particular challenges and vulnerability of low SES immigrants, this study focused on high SES German immigrants in Switzerland. German immigrants in Switzerland represent immigrant families with disproportionately high and accredited parental qualifications and a high SES. In $2011,71 \%$ of the German immigrant population in Switzerland reported being highly educated (university entrance qualification or higher) with over 50\% working as executives or in high academic positions (Eurostat, 2017), numbers that are also represented in our sample. Moreover, most of them (more than 70\%) migrated for economic reasons. Switzerland offers a high number of high quality and well-paid jobs that allow even those highly qualified immigrants to further improve their standard of living (Engler et al., 2015). As a result, German immigrants usually experience a rise in socio-economic status rather than a decline through their immigration to Switzerland. However, even though Germany and Switzerland are characterized by comparable cultural (e.g., individualistic) values (Hofstede, 2001), German immigrants in Switzerland report typical immigration-related phenomena. Families report language problems because Swiss-German, the dialect that is spoken by about $90 \%$ of Swiss in German-speaking Switzerland, is hardly understandable to most native Germans. It has differences in pronunciation, vocabulary (e.g., different designation of weekdays), and grammar from standard German spoken in Germany (Helbling, 2011; Schüpbach, 2014). Furthermore, German immigrants perceive hassles of social integration and perceived discrimination. Immigration-related hassles are reported to emerge from a perceived cultural and economic threat brought in by highly educated and highly qualified immigrants (Freitag \& Rapp, 2013). Cultural threat emerges from different cultural practices (e.g., forms of greeting and interpersonal interaction) and the traditional approach of Swiss immigration policies that is aimed at protecting "Swiss culture" against foreign influences (Manatschal, 2012). Economic threat is reported among well-educated Swiss in high positions or Swiss who seek to improve their job positions because they see their opportunities reduced, particularly by highly skilled immigrating Germans (Helbling, 2011). These hassles are more pronounced among working adults, leading adolescents to adopt roles as culture brokers and support their parents in social integration even ten years and more after immigration (Aumann \& Titzmann, 2020; Helbling, 2011). This is supported by research in other contexts that also revealed that acculturation is a life-long process. Culture brokering, for example, can even be found in second- and third-generation immigrant families (Buriel, 2012). 
The study of German immigrants in Switzerland is, thus, an ideal context for research on technical brokering. First, due to the high SES, the vast majority of German immigrant families studied has access to new technologies, which is a prerequisite of the examination of adolescents' technicalrelated responsibilities in their family. In addition, the high SES and education among German immigrant parents allows us to study immigration-related processes without the typical confound between migration and low socio-economic standing (Wang \& Miller, 2020). The Swiss context is also particularly well-suited for a study on technical brokering because Switzerland is highly innovative with widespread implementation and use of new ICT (Global Innovation Index, 2020).

\section{Technical Brokering in Immigrant Families: A Generational or Migration-related Phenomenon?}

Besides studying high SES immigrant adolescents and their families, this study applied a developmental (technical competence gaps between generations, family support general normative task in adolescence) and an acculturative perspective (technical brokering as part of adolescents support in parental acculturative adjustment) in explaining technical brokering. Studies showed that youths' support for their parents can be nurtured by a wide range of general (time constrains of employed parents, family circumstances such as parental divorce or illness, gender) and migrationspecific (socio-cultural adaptation difficulties from parents, culture brokering) factors in immigrant families (Aumann \& Titzmann, 2020; Hooper, 2016). In some families these general and acculturative factors accumulate resulting in higher levels of youths' family involvement (Portes et al., 2005). With regard to technical brokering, however, the unique contribution of migration-specific and general factors in explaining adolescents' technical brokering in families needs more evidence. The current study addressed this issue with respect to technical brokering in two ways. Firstly, if technical brokering is (at least partly) fostered by migration-specific processes, comparisons of native and immigrant adolescents should show higher levels of technical brokering among immigrant adolescents. Secondly, if technical brokering is fostered by migration-specific processes, migration-related predictors should explain variance in technical brokering in addition to general predictors of adolescents' technical brokering.

Several factors suggest the significance of technical brokering in immigrant families. Immigrant adolescents and their families often strive for keeping in touch with family and friends in their country of origin, and ICT enables this connection. In this regard, as "digital natives" (Prensky,
2001), German immigrant adolescents can ease the chatting and internet visits for family members (Kam \& Lazarevic, 2014). ICT also enable access to products from the country of origin through online shopping and provides information about the receiving country-a key to connecting with the local society (Moser, 2009). Moreover, youth can contribute to their families' adaptation by connecting their family to the host community (Fawcett, 2018; Katz, 2011). As one example, adolescents can write emails for parents in the local dialect to ease the communication with members of the host society (Schüpbach, 2014). These arguments endorse the particular meaning of ICT in immigrant families, and underscore how adolescents can support their families in the adaptation process by providing technical brokering. Thus, these findings suggest higher levels of technical brokering among German immigrant as compared to native Swiss adolescents.

However, group comparisons are not the only way to disentangle migration-specific and general aspects of technical brokering. Combining general and migrationspecific predictors is another approach (Titzmann \& Lee, 2018). Concerning general, migration-unrelated predictors, adolescents' gender may explain interindividual differences in technical brokering. Males tend to report higher competence in using ICT, more frequent use, and higher support for other family members than females. As one result, sons are oftentimes responsible for ICT in the family (Correa, 2010; JIM, 2018). This gender distribution is compelling as it contrasts with findings on traditional household tasks and culture brokering, where females provide higher levels of brokering (Weisskirch, 2005). Besides gender, parental involvement in other responsibilities may be related to technical brokering, in particular in the high SES group studied. German immigrants are known to mainly migrate for occupational reasons to Switzerland and to hold high status occupational positions, which are strongly related to high job engagement (Helbling, 2011). Research has shown that parental job engagement is positively linked to the amount of responsibilities adolescents adopt in their families (Greenhaus \& Beutell, 1985). Hence, including parental education and job status (as proxy for parental job engagement; Greenhaus \& Beutell, 1985) allows us to investigate general time constraints of parents in the prediction of technical brokering. In addition, we included adolescents' age, whether they live with one or two parents, and siblings as well-known predictors of adolescents' role in families.

Regarding migration-specific variables, cultural orientation, in particular, may affect technical brokering and both ethnic as well as host orientation may foster technical brokering. On the one hand, ICT has been shown to ease the transition into new environments for the whole family (Guan, 2017). A host orientation may therefore be 
associated with more technical brokering. On the other hand, an ethnic orientation may also instigate more technical brokering because a strong ethnic orientation can hinder adaptation to the Swiss context. Hence, immigrants may seek more contact with family and friends abroad (Birman \& Trickett, 2001). With regard to acculturative variables, we also included length of residence in Switzerland, Swiss language use, and Swiss language difficulties. Furthermore, some studies suggested that migration-specific helping behavior might foster other (migration-unspecific) forms of support of adolescents. In particular culture brokering, a known predictor of general family support, may be related to technical brokering with adolescents providing high levels of culture brokering also providing high levels of technical brokering (Aumann \& Titzmann, 2020; Weisskirch, 2020). However, the association between culture brokering and technical brokering may not be similar in strength between families. We expected culture brokering to be more strongly related to technical brokering when families report higher levels of socio-cultural adaptation difficulties (difficulties with the cultural customs, norms and value system of the host society and in managing social interactions; Ward \& Kennedy, 1999)—a family situation in which adolescents' support for their family's adaptation to the new society has a particular salience for families that may exacerbate technical brokering. This may in particular be the case among the German immigrant families studied, who are often perceived as cultural and economic threat for native Swiss and, thus, experience substantial adaptation difficulties (Freitag \& Rapp, 2013). In addition, research on brokering in LatinX families has shown, for instance, an increased intrafamilial support by adolescents when they are aware of the need of their support and the role they assume in the family (Fuligni \& Telzer, 2012). We therefore expected the association between culture brokering and technical brokering to be moderated by families' sociocultural difficulties.

Based on these considerations, we expected to find substantial levels of technical brokering in both samples. We assumed, however, that German immigrant adolescents would report providing technical brokering more frequently than native Swiss adolescents (H1) because of the salience of ICT for immigrant families. To examine whether general migration-unrelated or migration-related predictors better explain interindividual differences in technical brokering, we focused on the German immigrant group to be able to include both groups of predictors in the analysis. Older adolescents, adolescents with single-parents, adolescents with fewer siblings, and adolescents of parents in high occupational positions should report higher levels of technical brokering (H2a). Independently, those adolescents, who immigrated recently reported difficulties in adaptation, had a stronger orientation towards their ethnic culture, had a stronger orientation to the host culture, and reported higher levels of culture brokering are expected to report higher levels of technical brokering (H2b). Finally, we assumed that the association between culture brokering and technical brokering would be stronger when adolescents report more families' adaptation difficulties (H3).

\section{Methods}

\section{Sample}

Data collection in Switzerland took place in nine schools in the Canton of Zurich in 2013 and 2014, supported by the education authority of the canton. The data originated from the project "Adolescent Immigrants from Germany in Switzerland: Challenged or Fostered?" funded by the Foundation Suzanne and Hans Biäsch. This study was approved by the Institutional Review Board. The nine schools were spread across different districts of Zurich. All German immigrant youth of these schools were invited to participate. Participation in the study was voluntary. All participants were told that they were free to withdraw their consent to participate at any time without negative consequences. Inclusion criteria for participation were the following: adolescents aged between 12 and 18 years, and, for German immigrants in Switzerland, adolescents who emigrated from Germany to Switzerland or whose parents emigrated from Germany to Switzerland before the adolescents' birth. Native Swiss who described themselves as foreigners were excluded. Based on the criteria, 23 adolescents were eliminated before the analyses. The final sample comprised 301 adolescents: 165 native Swiss adolescents $\left(\mathrm{M}_{\mathrm{age}}=15.9\right.$ years $(\mathrm{SD}=1.5), 60.6 \%$ female $)$ and 136 German immigrant adolescents $\left(M_{\text {age }}=15.3\right.$ years $(\mathrm{SD}=1.8), 64.7 \%$ female, $\mathrm{M}_{\text {length of residence }}=10.2(\mathrm{SD}=$ 5.0)). $82 \%$ of the German immigrant fathers and $41 \%$ of the German immigrant mothers worked as senior or higher employee, civil servant or were self-employed. $73 \%$ of German immigrant fathers and 59\% of German immigrant mothers had at least a university qualification. Among native Swiss parents, $67 \%$ of the fathers and $36 \%$ of the mothers worked as senior or higher employee, civil servant or were self-employed and $47 \%$ of fathers and $37 \%$ of mothers had at least a university qualification.

\section{Measures}

Participants completed well-established, standardized questionnaires including validated measures with an online tool in the computer labs of each school or in paperpencil format when schools did not have sufficient computers available (Birman \& Trickett, 2001; Mesch, 2012; 
Ryder et al., 2000; Titzmann et al., 2011; Trickett \& Jones, 2007; Ward \& Kennedy, 1999). We verified measurement equivalence across three age groups-early (12-14 years), middle (15-16 years), and late (17-18 years) adolescenceto ensure that adolescents understood the items the same regardless of their stage of development. Analyses across the three age groups by using exploratory factor analyses and Tucker's congruence coefficient (van de Vijver \& Poortinga, 2002) showed a very good fit for all scales $(\phi \geq$ $0.99)$. Tests also showed measurement equivalence across the two groups studied (native Swiss vs. German immigrant; $\phi=0.99$ ).

\section{Demographic and family variables}

Adolescents reported their age, gender, whether they lived in a single-parent household (due to divorce or widowhood), number of siblings, parental education, and parental occupational status by answering six straightforward questions. To measure parental education, adolescents indicated the highest level of maternal and paternal completed education on an internationally comparable scale (International Standard Classification of Education [ISCED]) ranging from 0 (No school level qualification) to 5 (Doctoral degree). The German immigrants were additionally asked when they migrated to Switzerland.

\section{Technical brokering}

Technical brokering was measured with seven items on a four-point Likert scale (ranging from "never" to "almost daily") derived from Mesch (2012). Items were introduced as follows: "There are tasks that adolescents can assume in the family. Please rate how often you have done the following chores in the last month." and referred to seven tasks related to ICT, such as, "How often have you helped your parents to buy online in the last month?" These items were not migration- or culture-specific, so that they were able to be investigated among native and immigrant adolescents. The alpha consistency of this scale was high with $\alpha=0.86$ among German immigrants and native Swiss.

\section{Culture brokering}

Culture brokering was measured with six items (adapted scale of Trickett and Jones (2007)), such as, "How often did you schedule appointments for your parents because you know the language or the Swiss culture better?" Adolescents responded using a six-point Likert scale ranging from "never" to "very often." The alpha consistency of this scale was high among German immigrants $(\alpha=0.86)$, and this scale has already shown predictive validity in other studies (Aumann \& Titzmann, 2020).

\section{Swiss language use}

Swiss language use was assessed with six items on a fivepoint Likert scale ranging from "never" to "always" (Birman \& Trickett, 2001), e.g., "How often do you speak Swiss German with your friends?" The alpha consistency of this scale was high among German immigrants $(\alpha=0.82)$.

\section{Swiss language difficulties}

Adolescents' Swiss language difficulties were measured with five items, using a five-point Likert scale ranging from "never" to "more than ten times" (Titzmann et al., 2011), i.e., "I had problems at school because my Swiss German was not good enough." The alpha consistency of this scale was high among German immigrants $(\alpha=0.76)$.

\section{Host and ethnic culture orientation}

Adolescents' host and ethnic culture orientation both consisted of three items and included items such as, "I prefer to spend time with Germans/native Swiss" (Ryder et al., 2000). Adolescents responded using a six-point Likert scale ranging from, "does not apply" to "apply." The alpha consistency of this scale was high among German immigrants (host: $\alpha=0.74$; ethnic: $\alpha=0.75$ ).

\section{Socio-cultural adaptation difficulties}

Families' socio-cultural adaptation difficulties were assessed with eleven items on a five-point Likert scale (ranging from "no difficulties" to "extreme difficulties;" Ward \& Kennedy, 1999), such as, "How many difficulties have you experienced making friends in Switzerland?" The alpha consistency of this scale was high among German immigrants $(\alpha=0.77)$.

\section{Data analytic strategy}

To investigate technical brokering, we compared the seven tasks separately as well as in combination (the overall technical brokering score). The overall technical brokering score consisted of an index, which was a sum score of the number of technical brokering tasks reported by adolescents $(0=$ task never occurred, $1=$ task occurred at least once in the last month). We used this sum score because we were interested in the variety of tasks and not in a measure where performing one task frequently can compensate for not performing other tasks (which would be represented by a mean score). All analyses were conducted in SPSS Version 26. To examine group differences in technical brokering (Hypothesis 1), we conducted a multivariate ANOVA. To test Hypotheses 2 and 3, we used hierarchical regression 
Table 1 Pairwise comparisons of technical brokering tasks between ethnic groups

\begin{tabular}{llllll}
\hline $\begin{array}{l}\text { Please rate how often you have done the following } \\
\text { chores in the last month. }\end{array}$ & Ethnic group & M & F & $p$ \\
\hline 1 Using the Internet on behalf of my family & Native Swiss & 2.12 & 0.668 & 6.04 & 0.015 \\
& German immigrants & 2.36 & 0.971 & & \\
2 Help my family buy online & Native Swiss & 1.35 & 0.577 & 128.90 & $<0.001$ \\
& German immigrants & 2.67 & 1.311 & & \\
3 Advice/inform my family about products/goods via & Native Swiss & 1.45 & 0.704 & 279.40 & $<0.001$ \\
Internet & German immigrants & 2.90 & 0.778 & & \\
4 Explaining the Internet to my family (e.g., Skype. & Native Swiss & 1.66 & 0.677 & 0.59 & 0.441 \\
Facebook) & German immigrants & 1.60 & 0.847 & & \\
5 Writing/reading/answering emails for my parents & Native Swiss & 1.25 & 0.596 & $112.41<0.001$ \\
& German immigrants & 2.14 & 0.836 & & \\
\multirow{2}{*}{ Teaching my family how to download music } & Native Swiss & 1.34 & 0.584 & 6.51 & 0.011 \\
& German immigrants & 1.54 & 0.759 & & \\
7 Using the Internet for someone else & Native Swiss & 1.62 & 0.732 & $33.79<0.001$ \\
& German immigrants & 1.19 & 0.479 & & \\
\multirow{2}{*}{ Sum score (number of tasks performed) } & Native Swiss & 3.28 & 2.05 & $19.51<0.001$ \\
& German immigrants & 4.19 & 1.36 & & \\
\hline
\end{tabular}

analysis. In the first step we included general predictors and in the second step migration-specific predictors of technical brokering. In the last step, we added the interaction term. This allowed us to investigate the predictive power of migration-specific predictors beyond general predictors.

\section{Results}

To test the first hypothesis, we compared technical brokering in seven tasks between native Swiss and German immigrant adolescents. Table 1 presents the results separated for each task. German immigrants reported supporting their parents more frequently than native Swiss adolescents in five out of seven tasks (using internet for family, buying online, advising about products, writing emails, downloading music). The task "using internet for someone else" was reported more frequently by native Swiss adolescents, whereas no significant differences between both groups were found for "explaining internet". In the sum score, German immigrants reported supporting their parents in more domains related to ICT than native Swiss adolescents $(F(1,300)=19.51, p<0.001)$. Hence, Hypothesis 1 was supported.

Additional descriptive analyses reveled gender differences. Regarding the sum score, results revealed a gender effect in the native Swiss group, with males reporting higher levels of technical brokering than females (males = 3.74 , females $=2.99 ; F(1,164)=5.39, p<0.05)$, but no gender differences were observed in the German immigrant group $($ males $=4.44$, females $=4.06 ; F(1,135)=2.47$, $p=0.12$ ). With regard to single items, we found only three differences. In the native Swiss group, males reported more "advising about products" $($ males $=1.68$, females $=1.31$; $F(1,164)=10.44, p<0.01)$ and more downloading music $($ males $=1.60$, females $=1.18 ; F(1,164)=20.94$, $p<0.001)$ than females. In the German immigrant group, males reported more technical brokering in "downloading music" $($ males $=1.81$, females $=1.39 ; F(1,135)=10.47$, $p<0.01)$ than females.

To test Hypotheses 2 and 3, we used hierarchical regression analysis. These hypotheses stated that general family and acculturative variables predict technical brokering ( $\mathrm{H} 2 \mathrm{a} \& \mathrm{~b}$ ), and that culture brokering is more strongly related to technical brokering when adolescents report socio-cultural adaptation difficulties (H3). Again, we were interested in interindividual differences in the number of tasks that adolescents adopt. Hence, we used the sum score of reported tasks as outcome for multivariate regressions. As acculturation-related variables were only assessed in the immigrant group, these analyses were restricted to the German immigrant sample. The results in Table 2 show that with regard to general family variables only living in a single-parent family was marginally significant $(\beta=0.16, p=0.059)$ in the prediction of technical brokering. When including acculturative variables, the increase in the explained variance reached significance $\left(\Delta R^{2}=0.15\right.$, $\Delta F=3.80, p<0.01)$. The analysis showed that culture brokering $(\beta=0.36, p<0.001)$ explained most of the variance, which supported the generalization assumption of culture to technical brokering. In addition, ethnic $(\beta=-0.27, p<0.05)$ orientation was negatively related to technical brokering. The predictor host culture orientation was marginally significant $(\beta=0.23, p=0.057)$. Thus, Hypothesis $2 \mathrm{a}$ was only 
Table 2 Hierarchical regression analysis on technical brokering in the German immigrant group

\begin{tabular}{lrrrr}
\hline & $\beta$ & SE & T & $p$ \\
\hline Step 1 & & & & \\
Constant & & 1.34 & 2.48 & 0.014 \\
Single-parent family & 0.16 & 0.26 & 1.90 & 0.059 \\
Number of siblings & 0.07 & 0.14 & 0.69 & 0.492 \\
Age & 0.01 & 0.07 & 0.06 & 0.953 \\
Work father & 0.01 & 0.12 & 0.02 & 0.986 \\
Work mother & 0.12 & 0.09 & 1.37 & 0.173 \\
Education father & -0.13 & 0.15 & -0.93 & 0.352 \\
Education mother & 0.10 & 0.15 & 0.72 & 0.475 \\
Step 2 & & & & \\
Length of residence & 0.16 & 0.03 & 1.37 & 0.172 \\
Swiss language use & 0.07 & 0.14 & 0.62 & 0.535 \\
Ethnic acculturation & -0.27 & 0.21 & -2.33 & 0.021 \\
Host acculturation & 0.23 & 0.21 & 1.93 & 0.057 \\
Swiss language difficulties & 0.07 & 0.23 & 0.71 & 0.477 \\
Adaptation difficulties & 0.01 & 0.26 & 0.09 & 0.921 \\
Culture brokering & 0.36 & 0.14 & 3.96 & 0.000 \\
Step 3 & & & & \\
Culture brokering x adaptation & 0.18 & 0.35 & 2.01 & 0.047 \\
difficulties & & & & \\
& $F(15,120)=2.28, p=0.007$, \\
& $R^{2}=0.22$ & & \\
\hline & & & &
\end{tabular}

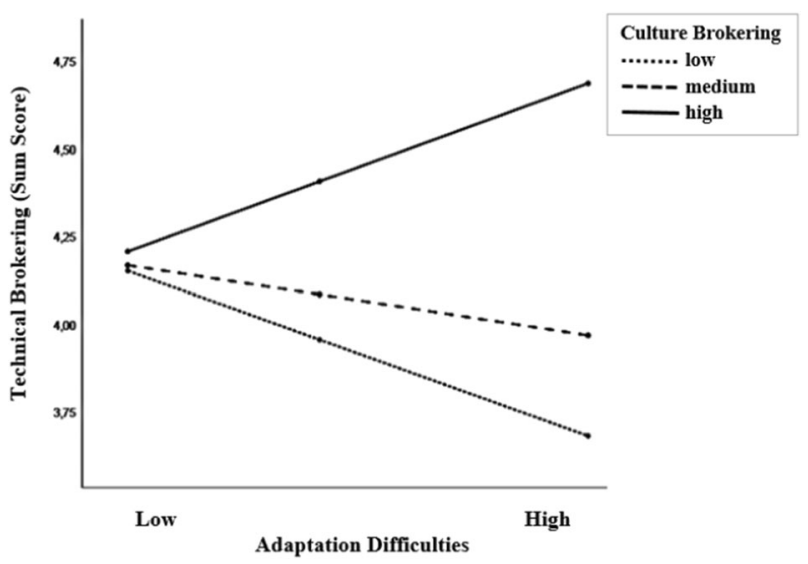

Fig. 1 Interaction of culture brokering and adaptation difficulties in the prediction of technical brokering

supported for single-parent families, whereas Hypothesis $2 b$ was supported with respect to culture brokering and host culture orientation. The interaction of culture brokering and adaptation difficulties also reached significance $(\beta=0.18$, $p<0.05$ ); high levels of culture brokering were strongly related to high levels of technical brokering when adolescents reported high adaptation difficulties (Fig. 1). Thus, Hypothesis 3 was supported.

\section{Discussion}

The starting point of this research was the question of whether technical brokering in high SES immigrant families is rather fostered by migration-related or general developmental family processes. Our results showed substantial levels of technical brokering in nearly all families studied, which underscores adolescents' active and meaningful role in families. Among German immigrants in Switzerland, however, the overall level of technical brokering was particularly high suggesting that migrationspecific (e.g., culture brokering, socio-cultural adaptation difficulties) in addition to general developmental processes explain elevated levels of adolescents' support in ICT in families. Moreover, technical brokering seems particularly associated with the ability of German immigrant families to cope with the transition to the new country. Host orientation and culture brokering (particularly when families experienced adaptation difficulties) were noticeable predictors of technical brokering. Furthermore, culture brokering was the most important predictor for technical brokering, which supports the assumption that youth' domain-specific support can generalize to other domains of family responsibilities. These findings suggest that the implications of technical brokering can go beyond providing support in ICT and facilitate immigrants' adaptation process in a new environment.

Our analyses showed that German immigrants reported higher levels of technical brokering than the native comparison sample of native Swiss adolescents. Results, however, also revealed that adolescents from both groups highly supported their parents by adopting ICT-related tasks, for example doing online-shopping for them. Thus, as both groups reported assisting their parents in many technical tasks, this study highlights that technical brokering is a phenomenon that seems, to some extent, normative in Western, educated and comparable wealthy families with access to ICT, but it can be further elevated by migration-specific processes (Van den Bulck et al., 2016). This finding complements research on low-income minority and immigrant families (e.g., LatinX families) in the US (e.g., Katz, 2011) and expands their findings by showing that immigrant adolescents' family support is not restricted to low-income immigrant families. Our results also suggested that technical brokering is not only the result of competence differences in the use of ICT between parents and their children. Rather, other processes, such as their usefulness in adaptation processes in immigrant families or parents' time constraints (e.g., among divorced parents) also seem to foster adolescents' ICT-related support for their parents because as "digital natives" adolescents often solve these tasks more efficiently than their parents (Prensky, 2001). 
We were also able to show that interindividual differences in technical brokering in the immigrant sample were best explained by culture brokering. Furthermore, the interaction of culture brokering and adaptation difficulties showed that high levels of culture brokering were strongly related to high levels of technical brokering when adolescents reported high adaptation difficulties. These findings, together, underscore the interpretation that technical brokering in our study was particularly associated with adolescents supporting their family in mastering the transition to a new country. However, previous research has revealed interfamilial differences as well as domain- and contextspecific effects in acculturation gaps. In some domains or contexts, parents were shown to be more strongly oriented to the host culture than their offspring (Aumann \& Titzmann, 2018). To shed some light on this interfamilial variability, future research on technical brokering may specifically study immigrant families in which acculturation gaps do not follow the average trend.

Against our assumptions, ethnic orientation predicted lower levels of technical brokering. This suggests that the adolescents in our study supported their parents primarily in adaptation to the Swiss culture by using ICT. Adolescents, who are more strongly oriented towards Germany, may be less supportive of the move to Switzerland. In this situation, they are probably less willing to support their parents. Similar effects based on the migration motivation are also observable in other immigrant groups (Silbereisen et al., 1999). This finding may also be a result of this particular sample. On average, the German families immigrated to Switzerland about 10 years ago and, after a decade of residence, their focus may be more on the successful integration into the new environment than on keeping contact with family and friends abroad. This is especially likely as research showed that German immigrants in Switzerland still reported adjustment difficulties after more than 10 years of residence (Helbling, 2011), which underscores that acculturation is a long process rather than a short period of adaptation (Buriel, 2012; Oppedal \& Toppelberg, 2016). Of course, both these interpretations are somewhat speculative and require more in-depth research.

We also found gender differences in technical brokering with males reporting that they provide technical brokering more frequently than females, in particular in the native Swiss group. This gender effect was in line with gender differences in the ICT literature (JIM, 2018). We cannot say whether the migration to Switzerland or the overall higher level of technical brokering abolished gender differences in the German immigrant sample or whether gender differences are smaller in Germany in general. The difference found calls for more comparative research including a native sample in Germany. However, this gender difference is compelling since it contradicts findings on culture brokering and the general distribution of chores in a household, which is commonly more frequently provided by females (Weisskirch, 2005). This result suggests that female adolescents do not necessarily support their parents more in general in the adaptation process - as often assumed in acculturation research based on findings on culture brokering-but that only the domains of responsibilities of male and female adolescents (still) seem to differ.

Our findings, however, have to be seen against the backdrop that German immigrants are not the typical immigrants studied. They are highly educated and comparatively wealthy, with a smaller cultural distance to the host society. Hence, our results may not necessarily be transferable to immigrant groups who experience a socio-economic decline or a large cultural distance. The results of this group of immigrants are, nevertheless, of high interest in acculturation research. The findings show that some effects studied in migration research (e.g., culture brokering) can also be observed in high status immigrant groups with a small cultural distance from the host society and are not solely explained by a decline in socio-economic standing that accompanies the migration process in many frequently studied immigrant groups. Moreover, it allowed us to differentiate general family and migration-specific processes in the prediction of technical brokering, because high SES immigrants do not show the typical confound between migration processes and family circumstances due to a low socio-economic standing (Wang \& Miller, 2020). However, studies on individualistic and high SES immigrant families are particularly scarce, although this type of migration is the most prevalent within Western Europe (Favell, 2008). Since ageing societies are in need of a qualified workforce, research has to pay greater attention on these samples to provide these families with evidencebased support.

Future research should consider additional aspects of technical brokering, such as the specific aims of use, technical knowledge of parents and adolescents, or access to ICT. In addition, a more detailed examination of the interplay of various migration-related and migrationunrelated support behaviors, together with cultural differences in family obligation values (Fuligni \& Telzer, 2012), and the inclusion of diverse immigrant samples and contexts, is crucial to better understand the interplay of culture, migration, and SES in immigrant family dynamics (Wang \& Miller, 2020). Refugees, for instance, may use technologies for other purposes (e.g., keeping contact with family and friends abroad) than German immigrant adolescents, who help their parents in adapting to the Swiss context, and native youths, who may see ICT support as one of many other potential tasks (e.g., household tasks or caring for siblings) (Awad \& Tossell, 2021). 
A limitation of these findings is the different formats of assessment (paper-pencil vs. computer), which may affect the results. Using two different written formats resulted from the fact that not all schools could provide sufficient computer labs, so that in some schools only a data collection by paper-pencil questionnaires was feasible. Nevertheless, both versions are written formats and have been found to reach similar results so that it is unlikely that our results are biased (Joubert \& Kriek, 2009). Another limitation is that only adolescents were studied, but no other family members. As the performance of providing cultural or technical support not only depends on the adolescents but also on the behavior of parents or siblings, it would be insightful to involve these family members in further research to holistically understand family dynamics (Juang $\&$ Syed, 2019). Furthermore, we were unable to specify which kind of music or products adolescents purchased for their families and whether or not they were culture-specific. In-depth qualitative methods may give answers to these questions in future research.

This study investigated general developmental and acculturation-related predictors of technical brokering. It is important to differentiate these processes, because a solely focus on acculturative processes disregards the developmental aspects of intrafamilial dynamics and a solely focus on developmental processes disregards the migrationspecific needs of immigrant families. In this study, acculturation-related processes explained most variance in technical brokering and it turned out that technical brokering is primarily related to German immigrant adolescents' support of their families' socio-cultural adaptation. The result may differ for other groups and other outcomes. Among immigrants from the former Soviet Union, for example, the developmental aspects explained more variance in reported victimization than acculturative variables (Jugert \& Titzmann, 2017). Hence, the claimed urgent need to combine acculturative and developmental aspects (Juang \& Syed, 2019; Schwartz et al., 2020) remains a growing task for scholars in this field.

Given the developmental opportunities that are inherent in adolescents' taking on family responsibilities (Fuligni \& Telzer, 2012; Weisskirch, 2020), research may also profit from the continued study of adolescents' brokering and family support in different domains, cultures, countries, and socio-economic contexts. Our study contributes to a more positive view on immigrant adolescents by highlighting the active role of adolescents in the adaptation of their families, a focus that has long been called for in the respective literature (Guan, 2017; Weisskirch, 2020). In this regard, our study complements research on immigrant families which primarily addressed the risks of adolescents' adoption of tasks in families (e.g., culture brokering or role reversal) by focusing on negative outcomes such as exhaustion, stress or depressive symptoms among youth (Shen et al., 2019). Future research on immigrant family dynamics will profit from a more balanced view on risks and opportunities of family support for their families. Such a risk and resilience perspective (Suárez-Orozco et al., 2018) will allow practitioners to derive practical recommendations that meet the specific needs of diverse families and to provide the most appropriate assistance for youth to thrive and for (future) societies to capitalize on its diversity.

Funding Open Access funding enabled and organized by Projekt DEAL.

\section{Compliance with Ethical Standards}

Conflict of interest The authors declare no competing interests.

Ethical Approval This study was approved by the Institutional Review Board.

Publisher's note Springer Nature remains neutral with regard to jurisdictional claims in published maps and institutional affiliations.

Open Access This article is licensed under a Creative Commons Attribution 4.0 International License, which permits use, sharing, adaptation, distribution and reproduction in any medium or format, as long as you give appropriate credit to the original author(s) and the source, provide a link to the Creative Commons license, and indicate if changes were made. The images or other third party material in this article are included in the article's Creative Commons license, unless indicated otherwise in a credit line to the material. If material is not included in the article's Creative Commons license and your intended use is not permitted by statutory regulation or exceeds the permitted use, you will need to obtain permission directly from the copyright holder. To view a copy of this license, visit http://creativecommons. org/licenses/by/4.0/.

\section{References}

Aumann, L., \& Titzmann, P. F. (2018). Acculturation gaps in diaspora immigrant adolescent-mother dyads: The case for a domain-, group- and context-specific view on family adaptation. International Journal of Psychology, 53, 3-12. https://doi.org/ 10.1002/ijop.12524.

Aumann, L., \& Titzmann, P. F. (2020). Why do youth support their families? A person-oriented approach in migrant and native families. Journal of Youth and Adolescence, 49(2), 506-519. https://doi.org/10.1007/s10964-019-01167-z.

Awad, I., \& Tossell, J. (2021). Is the smartphone always a smart choice? Against the utilitarian view of the 'connected migrant'. Information, Communication \& Society, 24(4), 611-626. https:// doi.org/10.1080/1369118X.2019.1668456.

Birman, D., \& Trickett, E. (2001). Cultural transitions in first-generation immigrants: Acculturation of Soviet Jewish refugee adolescents and parents. Journal of Cross-Cultural Psychology, 32(4), 456-477. https://doi.org/10.1177/0022022101032004006. (Not in File).

Buriel, R. (2012). Historical, socio-cultural, and conceptual issues to consider when researching Mexican American children and families, and other Latino subgroups*. Psychosocial Intervention, 21(3), 291-303. https://doi.org/10.5093/in2012a26. 
Cheung, B. Y., Chudek, M., \& Heine, S. J. (2011). Evidence for a sensitive period for acculturation: Younger immigrants report acculturating at a faster rate. Psychological Science, 22(2), 147-152. https://doi.org/10.1177/0956797610394661. (Not in File).

Correa, T. (2010). The participation divide among "Online experts": experience, skills and psychological factors as predictors of college students' web content creation. Journal of ComputerMediated Communication, 16(1), 71-92. https://doi.org/10. 1111/j.1083-6101.2010.01532.x.

Correa, T. (2014). Bottom-up technology transmission within families: exploring how youths influence their parents' digital media use with dyadic data. Journal of Communication, 64(1), 103-124. https://doi.org/10.1111/jcom.12067.

Correa, T., Pavez, I., \& Contreras, J. (2019). The complexities of the role of children in the process of technology transmission among disadvantaged families: a mixed-methods approach. International Journal of Communication, 13, 21.

Correa, T., Straubhaar, J. D., Chen, W., \& Spence, J. (2015). Brokering new technologies: the role of children in their parents' usage of the internet. New Media \& Society, 17(4), 483-500. https://doi.org/10.1177/1461444813506975.

Elias, N. (2013). Media and immigrant children. In D. Lemish (Ed.), The Routledge Handbook of Children, Adolescents and Media (pp. 336-343). Routledge.

Engler, M., Erlinghagen, M., Ette, A., Sauer, L., Scheller, F., Schneider, J., \& Schultz, C. (2015). Motive, Rahmenbedingungen und Folgen der Aus- und Rückwanderung deutscher Staatsbürger. Wiesbaden.

Eurostat. (2017). Zahl der geleisteten Wochenstunden bei Vollzeitbeschäftigten. Retrieved.

Favell, A. (2008). Eurostars and Eurocities: Free Movement and Mobility in an Integrating Europe. Blackwell Publishing. https:// doi.org/10.1002/9780470712818.

Fawcett, P. (2018). The information lives of immigrant and refugee youth acting as information and communication technology (ICT) wayfarers. [Dissertation, University of Washington]. Washington.

Ferguson, G. M., Muzaffar, H., Iturbide, M. I., Chu, H., \& Meeks Gardner, J. (2017). Feel american, watch american, eat american? Remote acculturation, TV, and nutrition among adolescent-mother dyads in Jamaica. Child Development. https://doi.org/10.1111/ cdev. 12808 .

Freitag, M., \& Rapp, C. (2013). Intolerance toward immigrants in Switzerland: diminished threat through social contacts? Swiss Political Science Review, 19(4), 425-446. https://doi.org/10. $1111 /$ spsr.12049.

Fuligni, A. J., \& Telzer, E. H. (2012). The contributions of youth to immigrant families. In A. S. Masten, K. Liebkind, D. J. Hernandez, A. S. Masten, K. Liebkind, \& D. J. Hernandez (Eds.), Realizing the potential of immigrant youth. (pp. 181-202). Cambridge University Press. http://search.ebscohost.com/login.aspx?direct= true $\& \mathrm{db}=$ psyh $\& A N=2012-14793-007 \&$ site $=$ ehost-live.

Global Innovation Index (2020). The Global Innovation Index 2019: Creating Healthy Lives-The Future of Medical Innovation. https://www.globalinnovationindex.org/gii-2019-report.

Greenhaus, J. H., \& Beutell, N. J. (1985). Sources of conflict between work and family roles. The Academy of Management Review, 10 (1), 76-88. https://doi.org/10.2307/258214.

Guan, S.-S. A. (2017). Immigrant Internetworks: Language Brokering and Internet Use. In R. S. Weisskirch (Ed.), Language Brokering in Immigrant Families: Theories and Contexts. Routledge.

Helbling, M. (2011). Why Swiss-Germans dislike Germans. European Societies, 13(1), 5-27. https://doi.org/10.1080/14616696. 2010.533784.

Hofstede, G. (2001). Culture's Consequences: Comparing Values, Behaviors, Institutions and Organizations Across Nations. Sage Publications. https://doi.org/10.1016/S0005-7967(02)00184-5
Hooper, L. M. (2016). The application of attachment theory and family systems theory to the phenomena of parentification. The Family Journal, 15(3), 217-223. https://doi.org/10.1177/ 1066480707301290.

Hurrelmann, K., \& Quenzel, G. (2018). Developmental tasks in adolescence. Routledge.

JIM. (2018). Jugend, Information, Media. Basisstudie zum Medienumgang 12- bis 19-Jähriger. mpfs.

Joubert, T. \& Kriek, H. J. Psychometric comparison of paper-andpencil and online personality assessments in a selection setting [online assessment; personality questionnaire; equivalence; Occupational Personality Questionnaire; paper-and-pencilassessment]. SA Journal of Industrial Psychology, 35(1), 78-88. https:// doi.org/10.4102/sajip.v35i1.727.

Juang, L. P. \& Syed, M. (2019). The evolution of acculturation and development models for understanding immigrant children and youth adjustment. Child Development Perspectives, 13(4), 241-246. https://doi.org/10.1111/cdep.12346.

Jugert, P., \& Titzmann, P. F. (2017). Trajectories of victimization in ethnic diaspora immigrant and native adolescents: Separating acculturation from development. Developmental Psychology, 53 (3), 552-566. https://doi.org/10.1037/dev0000254.

Jurkovic, G. J. (1997). Lost childhoods: The plight of the parentified child. Brunner/Mazel. http://search.ebscohost.com/login.aspx? direct $=$ true $\& \mathrm{db}=$ psyh $\& A N=1997-36274-000 \&$ site $=$ ehost-live.

Kam, J. A., \& Lazarevic, V. (2014). Communicating for one's family: an interdisciplinary review of language and cultural brokering in immigrant families. Annals of the International Communication Association, 38(1), 3-37. https://doi.org/10.1080/23808985.2014. 11679157.

Katz, V. S. (2010). How children of immigrants use media to connect their families to the community. Journal of Children and Media, 4(3), 298-315. https://doi.org/10.1080/17482798.2010.486136.

Katz, V. S. (2011). Children being seen and heard: How Youth contribute to their Migrant Families' Adaptation. Open University Press/Aresta Publications.

Livingstone, S. (2003). Children's use of the internet: Reflections on the emerging research agenda. New Media \& Society, 5(2), 147-166. https://doi.org/10.1177/1461444803005002001.

Livingstone, S., \& Haddon, L. (2009). EU Kids Online: final report 2009. London, UK: European Community Safer Internet Plus Programme and Sonia Livingstone: EU Kids Online Network

Manatschal, A. (2012). Path-dependent or dynamic? Cantonal integration policies between regional citizenship traditions and right populist party politics. Ethnic and Racial Studies, 35(2), 281-297. https://doi.org/10.1080/01419870.2011.573221.

Mesch, G. S. (2012). Technology and youth. New Directions for Youth Development, 2012(135), 97-105. https://doi.org/10.1002/ yd.20032.

Morris, M. W., Chiu, C.-y, \& Liu, Z. (2015). Polycultural psychology. Annual Review of Psychology, 66, 631-659. https://doi.org/10. 1146/annurev-psych-010814-015001.

Moser, H. (2009). Das Internet in der Nutzung von Jugendlichen mit Migrationshintergrund [The Internet in the use of youth with a migration background.]. In U. Hunger \& K. Kissau (Eds.), Internet und Migration: Theoretische Zugänge und empirische Befunde (pp. 199-212). VS Verlag für Sozialwissenschaften. https://doi.org/10.1007/978-3-531-91902-7_10.

Oppedal, B., \& Toppelberg, C. O. (2016). Acculturation development and the acquisition of culture competence. In D. L. Sam \& J. Berry (Eds.), The Cambridge handbook of acculturation psychology (pp. 71-92). Cambridge University Press.

Pedersen, S., \& Revenson, T. A. (2005). Parental illness, family functioning, and adolescent well-being: a family ecology framework to guide research. Journal of Family Psychology, 19(3), 404-419. https://doi.org/10.1037/0893-3200.19.3.404. 
Portes, A., Fernández-Kelly, P., \& Haller, W. (2005). Segmented assimilation on the ground: The new second generation in early adulthood. Ethnic and Racial Studies, 28(6), 1000-1040. https:// doi.org/10.1080/01419870500224117.

Prensky, M. (2001). Digital natives, digital immigrants part 1. On the Horizon, 9, 1-6. https://doi.org/10.1108/10748120110424816.

Redfield, R., Linton, R., \& Herskovits, M. J. (1936). Memorandum for the study of acculturation. American Anthropologist, 38, 149-152. https://doi.org/10.1525/aa.1936.38.1.02a00330. In File.

Ryder, A. G., Alden, L. E., \& Paulhus, D. L. (2000). Is acculturation unidimensional or bidimensional? A head-to-head comparison in the prediction of personality, self-identity, and adjustment. Journal of Personality and Social Psychology, 79(1), 49-65. https://doi.org/10.1037/0022-3514.79.1.49. In File.

Schüpbach, D. (2014). German or Swiss? Address and other routinised formulas in German-speaking Switzerland. In J. Hajek \& Y. Slaughter (Eds.), Challenging the Monolingual Mindset (pp. 63-77). St Nicholas House. https://doi.org/10.21832/9781783092529-007.

Schwartz, S. J., Walsh, S. D., Ward, C., Tartakovsky, E., Weisskirch, R. S., Vedder, P., Makarova, E., Bardi, A., Birman, D., Oppedal, B., Benish-Weisman, M., Lorenzo-Blanco, E. I., Güngör, D., Stevens, G. W. J. M., Benet-Martínez, V., Titzmann, P. F., Silbereisen, R. K., Geeraert, N., \& Psychology of Migration Working Group. (2020). The role of psychologists in international migration research: Complementing other expertise and an interdisciplinary way forward. Migration Studies. https://doi.org/ 10.1093/migration/mnz054.

Shen, Y., Kim, S. Y., \& Benner, A. D. (2019). Burdened or efficacious? Subgroups of Chinese American Language Brokers, Predictors, and Long-Term Outcomes. Journal of Youth and Adolescence, 48(1), 154-169. https://doi.org/10.1007/s10964018-0916-4.

Silbereisen, R. K., Lantermann, E. D., \& Schmitt-Rodermund, E. (1999). Aussiedler in Deutschland. Akkulturation von Persönlichkeit und Verhalten [Aussiedler in Germany. Acculturation of personality and behavior]. Leske \& Budrich.

Statista. (2020). Anteil der Internetnutzer in Deutschland bis 2019. [Proportion of Internet users in Germany until 2019.] https://de. statista.com/statistik/daten/studie/13070/umfrage/entwicklungder-internetnutzung-in-deutschland-seit-2001/\#professional.

Suárez-Orozco, C., Motti-Stefanidi, F., Marks, A., \& Katsiaficas, D. (2018). An integrative risk and resilience model for understanding the adaptation of immigrant-origin children and youth. American Psychologist, 73(6), 781-796. https://doi.org/10.1037/a mp0000265. New Directions in Developmental Science With Youth Experiencing Marginalization.

Telzer, E. H. (2010). Expanding the acculturation gap-distress model: An integrative review of research. Human Development, 53(6), 313-340. https://doi.org/10.1159/000322476.
Titzmann, P. F. (2012). Growing up too soon? Parentification among immigrant and native adolescents in Germany. Journal of Youth and Adolescence, 41(7), 880-893. https://doi.org/10.1007/ s10964-011-9711-1. (Not in File).

Titzmann, P. F., \& Lee, R. M. (2018). Adaptation of young immigrants: A developmental perspective on acculturation research. European Psychologist, 23(1), 72-82. 0.1027/1016-9040/a000313.

Titzmann, P. F., Silbereisen, R. K., Mesch, G. S., \& Schmitt-Rodermund, E. (2011). Migration-Specific hassles among adoelscent immigrants from the Former Soviet Union in Germany and Israel. Journal of Cross-Cultural Psychology, 42(5), 777-794. https:// doi.org/10.1177/0022022110362756.

Trickett, E. J., \& Jones, C. J. (2007). Adolescent culture brokering and family functioning: A study of families from Vietnam. Cultural Diversity and Ethnic Minority Psychology, 13(2), 143-150. https://doi.org/10.1037/1099-9809.13.2.143.

Tse, L. (1995). Language Brokering among Latino Adolescents: Prevalence, Attitudes, and School Performance. Hispanic Journal of Behavioral Sciences, 17(2), 180-193. https://doi.org/10.1177/ 07399863950172003.

van de Vijver, F., \& Poortinga, Y. H. (2002). Structural equivalence in multilevel research. Journal of Cross-Cultural Psychology, 33(2), 141-156. https://doi.org/10.1177/0022022102033002002. (In File).

Van den Bulck, J., Custers, K., \& Nelissen, S. (2016). The child-effect in the new media environment: challenges and opportunities for communication research. Journal of Children and Media, 10(1), 30-38. https://doi.org/10.1080/17482798.2015.1121897.

Wang, Z., \& Miller, J. G. (2020). Cost and Family Obligation in Everyday Sacrifice to Parents Among European American and Chinese Emerging Adults. Cross-Cultural Research, 54(2-3), 156-179. https://doi.org/10.1177/1069397119863422.

Ward, C., \& Kennedy, A. (1999). The measurement of sociocultural adaptation. International Journal of Intercultural Relations, 23 (4), 659-677. https://doi.org/10.1016/S0147-1767(99)00014-0. (Not in File).

Weisskirch, R. S. (2005). The relationship of language brokering to ethnic identity for latino early adolescents. Hispanic Journal of Behavioral Sciences, 27(3), 286-299. https://doi.org/10.1177/ 0739986305277931. (In File).

Weisskirch, R. S. (2020). Adolescent language brokers: developmental and familial considerations. In P. F. Titzmann \& P. Jugert (Eds.), Youth in Superdiverse Societies: Growing up with globalization, diversity, and acculturation. Routledge.

Yip, J., Gonzalez, C., \& Katz, V. (2016). The learning experiences of youth online information brokers. In C. K. Looi, J. L. Polman, U. Cress, \& P. Reimann (Eds.), Transforming Learning, Empowering Learners: The International Conference of the Learning Sciences (ICLS) 2016 (Vol. 1). International Society of the Learning Sciences. 